\title{
Confiança nas Forças Armadas brasileiras: uma análise empírica a partir dos dados da pesquisa SIPS - Defesa Nacional
}

\author{
Rubem Kaipper Ceratti \\ Bolsista do Programa Nacional de Pesquisa para o Desenvolvimento \\ Instituto de Pesquisa Econômica Aplicada \\ Rodrigo Fracalossi de Moraes \\ Técnico de Planejamento e Pesquisa \\ Instituto de Pesquisa Econômica Aplicada \\ Doutorando em Relações Internacionais \\ Departamento de Política e Relações Internacionais \\ Universidade de Oxford \\ Edison Benedito da Silva Filho \\ Técnico de Planejamento e Pesquisa \\ Instituto de Pesquisa Econômica Aplicada
}

\begin{abstract}
Resumo: Este artigo tem como propósito identificar os condicionantes associados ao grau de confiança da população brasileira nas Forças Armadas do país. A principal fonte de dados foi um survey nacional realizado pelo Ipea em 2011 no âmbito da pesquisa "Sistema de Indicadores de Percepção Social", com foco em questões relacionados à defesa e segurança (SIPS Defesa Nacional). A partir das informações coletadas no survey e à luz da literatura sobre o tema, construiu-se um conjunto de variáveis independentes, cujo impacto sobre a confiança foi então testado por meio de um modelo de regressão ordinal. A principal conclusão do trabalho é que, não obstante prevaleça um elevado nível de confiança nas Forças Armadas entre todos os estratos da população brasileira, essa confiança é impactada de forma distinta de acordo com os condicionantes socioeconômicos e regionais e a percepção dos indivíduos acerca da legitimidade e efetividade de determinadas políticas públicas.
\end{abstract}

Palavras-chave: Forças Armadas; Brasil; confiança; opinião pública; regressão ordinal

\begin{abstract}
This article aims to identify the variables associated to the Brazilian population trust in the country's Armed Forces. The main source of data is a national survey conducted by Ipea in 2011 through the research project "System of Indicators of Social Perception", with focus on defense and security issues. By organizing the survey data in the light of the literature on the subject, we built up a set of independent variables, whose impact on confidence was then tested using a model of ordinal regression. The main conclusion is that, despite prevails a high level of confidence in the military among all strata of the population, that trust is impacted differently according to socioeconomic and regional conditions, as well as the perception of individuals about the legitimacy and effectiveness of specific public policies.
\end{abstract}

Keywords: Armed Forces; Brazil; trust; public opinion; ordinal regression 


\section{Introdução}

Ainda há escassa pesquisa empírica no Brasil acerca de temas relacionados à defesa nacional, sobretudo no que tange às percepções da população sobre as instituições e políticas públicas desse setor. Isso se deve não apenas à carência de dados, mas ao fato de que as políticas de defesa e segurança nacional do país foram historicamente formuladas no âmbito das próprias Forças Armadas, com baixo envolvimento de outras instituições. Apenas em período recente o tema passou a ser debatido de forma mais ampla por outros segmentos do Estado e pela sociedade civil, no bojo da redemocratização do país e das mudanças nas atribuições institucionais das Forças Armadas a partir da criação do Ministério da Defesa em 1999.

Com o objetivo de subsidiar com informações os atores envolvidos com as políticas de defesa nacional no país, incluindo militares das Forças Armadas, técnicos do governo, parlamentares, diplomatas, acadêmicos, empresários e integrantes de organizações da sociedade civil, o Instituto de Pesquisa Econômica Aplicada (Ipea) realizou uma pesquisa de abrangência nacional acerca da percepção da sociedade sobre o tema, no âmbito do projeto do Sistema de Indicadores de Percepção Social (SIPS) ${ }^{1}$. Foram aplicadas 30 questões aos entrevistados, divididas em quatro eixos temáticos: i) percepção sobre a defesa nacional e as Forças Armadas; ii) percepção de ameaças; iii) poder militar do Brasil e inserção internacional; e iv) Forças Armadas e sociedade. Ao todo, foram ouvidas 3.796 pessoas, em todas as unidades da federação, entre os dias 8 e 29 de agosto de $2011^{2}$. A partir dos dados coletados, obteve-se um retrato da percepção da população brasileira em relação ao tema da defesa nacional e ao papel desempenhado pelas instituições vinculadas a essa área.

Embora constitua um componente essencial de diversas pesquisas relacionadas ao desempenho das instituições públicas e ao grau de adesão social a regimes democráticos, a confiança nas Forças Armadas brasileiras carece de investigação aprofundada sobre seus determinantes. A literatura aponta a prevalência de um elevado nível de confiança nas instituições militares em diversos países, como: Alemanha (BuLMAhn; FIeBIG; HILPERT, 2011), Canadá (MonTAlvo, 2009), Chile (MonTALVo, 2009), Colômbia (Montalvo, 2009), Espanha (NuÑEz, 2010), Estados Unidos (Montalvo, 2009; Gallup, 2012; Pew Research Center, 2013), Hungria (Kiss, 2003), Japão (Japan Ministry of Defense, 2012), México (Montalvo, 2009), Polônia (Gogolewska, 2003), Reino Unido (U.K. MıNISTRY Of Defence, 2012) e Suíça (HALTINER, 2003). Contudo, tal confiança parece estar associada a diferentes fatores, conforme o

\footnotetext{
1 O SIPS foi concebido com o objetivo de criar um conjunto de dados primários de percepção social capaz de fornecer ao Estado informações para subsidiar análises e decisões referentes a formulação, implementação e avaliação das suas políticas públicas, bem como oferecer à sociedade condições para melhor conhecer e avaliar os resultados efetivos alcançados pelas políticas públicas vigentes. Esses dados são coletados por meio de pesquisas de abrangência nacional. Para maiores informações sobre a metodologia de coleta e processamento de dados do SIPS, bem como os principais resultados da pesquisa SIPS - Defesa Nacional, ver: Oliveira Júnior, Silva Filho e Moraes (2012).

2 Para a pesquisa adotou-se uma abordagem quantitativa cujo método estatístico permitiu determinar por amostragem probabilística, com erro amostral de 5\% para o Brasil e regiões, e nível de confiança de $95 \%$, o tamanho da amostra de 3.796 domicílios para, assim, aferir a percepção da população sobre o fenômeno em questão. Para tanto, a amostragem foi decomposta em três etapas: i) na primeira, houve uma estratificação por regiões, mantendo-se tamanhos amostrais prefixados com margem de erro de $5 \%$. Dentro de cada estrato (região) houve sorteio dos municípios através de amostragem por conglomerados, controlando a distribuição por porte e unidade da federação; ii) na segunda etapa, já devidamente definidos os municípios amostrados, houve um sorteio dos domicílios, cujo critério aleatório foi composto por dois estágios: a) sorteio do setor censitário e b) arrolamento sistemático dos domicílios; iii) por fim, dada a definição prévia dos domicílios, adotou-se a amostragem sistemática das pessoas, cujo questionário era respondido por quem se encontrava presente em cada domicílio.
} 
caso analisado. Alguns países - notadamente europeus e asiáticos - possuem, em suas histórias contemporâneas, experiências de participação (ou de expectativa de participação) significativa em conflitos armados de grande magnitude, de modo que a confiança nas Forças Armadas está intimamente relacionada à necessidade de proteção da soberania. Outros países, como a maior parte dos latinoamericanos, muito embora se encontrem "em paz" por longo tempo, passaram, durante o século XX, por períodos de interrupção do funcionamento de suas instituições democráticas. Tais experiências podem influenciar a percepção das populações desses países acerca de suas Forças Armadas.

Dada, pois, a complexidade das variáveis relacionadas com a confiança depositada pela população nas instituições militares, bem como seu inevitável imbricamento com os efeitos de diversas outras políticas públicas, o emprego de técnicas estatísticas se mostra útil para avançar na compreensão desse fenômeno social. Este artigo busca, nesse sentido, oferecer uma contribuição a essa agenda de pesquisa por meio da análise estatística de uma série de fatores identificados no questionário do SIPS Defesa Nacional como possíveis elementos que se associam ao grau de confiança manifesto pela população brasileira nas Forças Armadas.

Este artigo está dividido em cinco seções, incluindo esta Introdução. A segunda seção apresenta a metodologia adotada neste estudo, que consiste no método de regressão ordinal. A terceira seção apresenta os resultados obtidos pela regressão e os testes para validação do modelo proposto. A quarta seção discute os dados obtidos a partir da análise estatística, descrevendo os efeitos marginais de cada variável pré-selecionada sobre a variável confiança nas Forças Armadas. Conclui-se destacando os elementos encontrados nessa análise empírica que contribuem para a explicação de variações no grau de confiança nas Forças Armadas brasileiras.

\section{Metodologia}

Para a análise dos dados de confiança nas Forças Armadas e sua relação com diversos atributos socioeconômicos previamente identificados, utilizou-se um modelo de regressão ordinal na estimação do efeito das variáveis independentes sobre a variável resposta.

A escolha das variáveis explicativas se deu a partir da revisão de pesquisas empíricas similares conduzidas em outros países (MonTALVo, 2009; LEAL, 2005; JAPAN MINISTRY OF DefENSE, 2012; GüRSOY, 2012). Com vistas a facilitar a identificação das variáveis selecionadas com as questões aplicadas no questionário SIPS - Defesa Nacional, optou-se por denominar essas variáveis como Q\#, em que \# segue a numeração da questão correspondente no formulário de pesquisa (reproduzido no Apêndice ao final do artigo).

A variável dependente do modelo é a confiança nas Forças Armadas (Q19). Foram escolhidas, ao total, 17 variáveis independentes, discriminadas no Quadro 1, a seguir, juntamente com suas respectivas categorias (no caso das variáveis qualitativas) ou faixas de valores (no caso das variáveis quantitativas): 
Quadro 1

Variáveis independentes selecionadas

a partir da pesquisa SIPS - Defesa Nacional

\begin{tabular}{|c|c|c|}
\hline Variável & $\begin{array}{l}\text { Número de } \\
\text { categorias }\end{array}$ & Descrição das categorias \\
\hline Sexo & 2 & $\begin{array}{ll}\text { 1. } & \text { Masculino } \\
\text { 2. } & \text { Feminino }\end{array}$ \\
\hline Região & 5 & $\begin{array}{ll}\text { 1. } & \text { Sul } \\
\text { 2. } & \text { Sudeste } \\
\text { 3. } & \text { Norte } \\
\text { 4. } & \text { Nordeste } \\
\text { 5. } & \text { Centro-Oeste } \\
\end{array}$ \\
\hline $\begin{array}{c}\text { Q1 } \\
\text { Idade }\end{array}$ & 6 & $\begin{array}{ll}\text { 1. } & 18 \text { a } 24 \text { anos } \\
\text { 2. } & 25 \text { a } 34 \text { anos } \\
\text { 3. } & 35 \text { a } 44 \text { anos } \\
\text { 4. } & 45 \text { a } 54 \text { anos } \\
\text { 5. } & 55 \text { a } 64 \text { anos } \\
\text { 6. } & \text { mais de } 64 \text { anos }\end{array}$ \\
\hline $\begin{array}{c}\text { Q2 } \\
\text { Escolaridade }\end{array}$ & 7 & $\begin{array}{ll}\text { 1. } & \text { Não escolarizado (a) } \\
\text { 2. } & \begin{array}{l}\text { Ensino fundamental } \\
\text { incompleto }\end{array} \\
\text { 3. } & \begin{array}{l}\text { Ensino fundamental } \\
\text { completo }\end{array} \\
\text { 4. } & \text { Ensino médio } \\
\text { incompleto } \\
\text { 5. } & \text { Ensino médio completo } \\
\text { 6. Superior incompleto } \\
\text { 7. Superior completo ou } \\
\text { pós-graduação }\end{array}$ \\
\hline $\begin{array}{l}\text { Q3 } \\
\text { Cor ou raça }\end{array}$ & 5 & $\begin{array}{ll}\text { 1. } & \text { Branca } \\
\text { 2. } & \text { Preta } \\
\text { 3. } & \text { Amarela } \\
\text { 4. } & \text { Parda } \\
\text { 5. } & \text { Indígena } \\
\end{array}$ \\
\hline $\begin{array}{c}\text { Q10 } \\
\text { Renda }^{1}\end{array}$ & 5 & $\begin{array}{ll}\text { 1. } & \text { Até } \mathrm{R} \$ 545,00 \\
\text { 2. } & \mathrm{De} \mathrm{R} \$ 545,01 \mathrm{a} \\
\text { 3. } & \mathrm{R} \$ 1.090,00 \\
\text { 4. } & \mathrm{De} \mathrm{R} \$ 1.090,01 \mathrm{a} \\
\text { 5. } & \mathrm{R} \$ 2.725,00 \\
\text { 6. } & \mathrm{De} \mathrm{R} \$ 2.725,01 \mathrm{a} \\
\text { 7. } & \mathrm{R} \$ 5.450,00 \\
\text { 8. } & \text { Acima de } \mathrm{R} \$ 5.450,00\end{array}$ \\
\hline $\begin{array}{c}\text { Q11 } \\
\text { Orgulho de ser brasileiro }\end{array}$ & 3 & 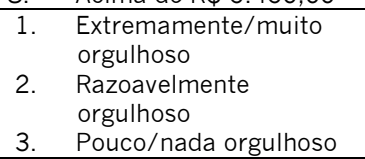 \\
\hline $\begin{array}{c}\text { Q12 } \\
\text { Serviu/serve/ } \\
\text { conhece quem serviu às } \\
\text { Forças Armadas }\end{array}$ & 3 & 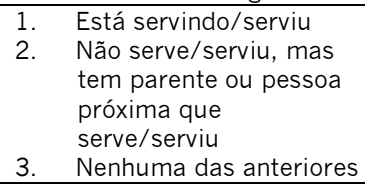 \\
\hline $\begin{array}{c}\text { Q13 } \\
\text { Avaliação do trabalho das } \\
\text { Forças Armadas }\end{array}$ & 3 & $\begin{array}{ll}\text { 1. } & \text { Muito bom/bom } \\
\text { 2. Regular } \\
\text { 3. Ruim/muito ruim }\end{array}$ \\
\hline $\begin{array}{c}\text { Q14 } \\
\text { Avaliação da } \\
\text { quantidade de informações } \\
\text { disponíveis sobre as } \\
\text { Forças Armadas }\end{array}$ & 3 & $\begin{array}{ll}\text { 1. } & \text { Muito boa/boa } \\
\text { 2. } & \text { Regular } \\
\text { 3. } & \text { Ruim/muito ruim }\end{array}$ \\
\hline
\end{tabular}


OPINIÃO PÚBLICA, Campinas, vol. 21, no 1, abril, 2015, p. $132-156$

\begin{tabular}{|c|c|c|}
\hline Variável & $\begin{array}{l}\text { Número de } \\
\text { categorias }\end{array}$ & Descrição das categorias \\
\hline $\begin{array}{c}\text { Q15 } \\
\text { Avaliação da } \\
\text { igualdade de tratamento } \\
\text { conferido pelas Forças } \\
\text { Armadas }\end{array}$ & 3 & 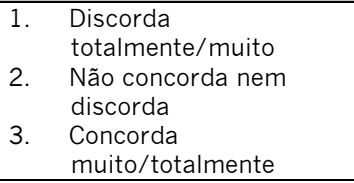 \\
\hline $\begin{array}{c}\text { Q16 } \\
\text { Encaminhamento de } \\
\text { reclamação ou denúncia contra } \\
\text { as Forças Armadas e/ } \\
\text { ou seus integrantes }\end{array}$ & 3 & $\begin{array}{l}\text { 1. Muito fácil/fácil } \\
\text { 2. De dificuldade razoável } \\
\text { 3. Difícil/muito difícil }\end{array}$ \\
\hline $\begin{array}{c}\text { Q17 } \\
\text { Autoavaliação quanto ao } \\
\text { nível de informação sobre as } \\
\text { Forças Armadas }\end{array}$ & 3 & $\begin{array}{ll}\text { 1. } & \text { Totalmente/muito } \\
\text { informado } \\
\text { 2. }\end{array}$ \\
\hline $\begin{array}{c}\text { Q18 } \\
\text { Importância das Forças } \\
\text { Armadas }\end{array}$ & 3 & $\begin{array}{l}\text { 1. Apenas no caso de uma } \\
\text { guerra } \\
\text { 2. Tanto no caso de uma } \\
\text { guerra como na } \\
\text { ausência de guerras } \\
\text { 3. Não são importantes em } \\
\text { nenhuma situação }\end{array}$ \\
\hline $\begin{array}{c}\text { Q31 } \\
\text { Participação das Forças } \\
\text { Armadas em } \\
\text { missões de paz } \\
\end{array}$ & 2 & $\begin{array}{l}\text { 1. Favorável } \\
\text { 2. Não favorável }\end{array}$ \\
\hline $\begin{array}{c}\text { Q38 } \\
\text { Respeito das Forças Armadas à } \\
\text { democracia }\end{array}$ & 3 & 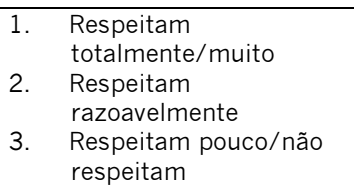 \\
\hline $\begin{array}{c}\text { Q39 } \\
\text { Conhecimento a respeito da } \\
\text { Lei da Anistia }\end{array}$ & 3 & $\begin{array}{l}\text { 1. Nunca tinha ouvido falar } \\
\text { 2. Tinha ouvido falar, mas } \\
\text { não sabe o que é } \\
\text { 3. Ouviu falar e sabe o que } \\
\text { é }\end{array}$ \\
\hline
\end{tabular}

Fonte: Elaboração própria com base no Formulário SIPS - Defesa Nacional, reproduzido no Apêndice ao final do artigo.

Nota: ${ }^{1}$ Para a divisão em níveis, considerou-se o valor do salário mínimo vigente entre março e dezembro de 2011 , com valor mensal de $\mathrm{R} \$ 545,00$.

O resultado esperado para o sentido da correlação e a intensidade dos efeitos produzidos pelas variáveis independentes é apresentado no Quadro 2: 
Quadro 2

Sentido esperado para as variáveis

independentes e probabilidade de simultaneidade

\begin{tabular}{|c|c|c|}
\hline Variável explicativa & $\begin{array}{l}\text { Sentido da correlação } \\
\text { com a variável confiança }\end{array}$ & Probabilidade de simultaneidade \\
\hline Sexo & - (mulheres) & Não se aplica \\
\hline Região & $+($ Norte e Sul) & Não se aplica \\
\hline $\begin{array}{c}\text { Q1 } \\
\text { Idade }\end{array}$ & . & Não se aplica \\
\hline $\begin{array}{c}\text { Q2 } \\
\text { Escolaridade } \\
\end{array}$ & - & Não se aplica \\
\hline $\begin{array}{c}\text { Q3 } \\
\text { Cor ou raça } \\
\end{array}$ & Indeterminado & Não se aplica \\
\hline $\begin{array}{c}\text { Q10 } \\
\text { Renda } \\
\end{array}$ & - & Não se aplica \\
\hline $\begin{array}{c}\text { Q11 } \\
\text { Orgulho de ser brasileiro } \\
\end{array}$ & + & Significativa \\
\hline $\begin{array}{c}\text { Q12 } \\
\text { Serviu/serve/conhece quem serviu às } \\
\text { Forças Armadas } \\
\end{array}$ & $\stackrel{+}{\stackrel{+}{(" s e r v i u / s e r v e / c o n h e c e ")}}$ & Não Significativa \\
\hline $\begin{array}{c}\text { Q13 } \\
\text { Avaliação do trabalho das Forças } \\
\text { Armadas } \\
\end{array}$ & + & Significativa \\
\hline $\begin{array}{c}\text { Q14 } \\
\text { Avaliação da quantidade de informações } \\
\text { disponíveis sobre as } \\
\text { Forças Armadas } \\
\end{array}$ & + & Não Significativa \\
\hline $\begin{array}{c}\text { Q15 } \\
\text { Avaliação da igualdade de tratamento } \\
\text { conferido pelas Forças Armadas }\end{array}$ & - & Significativa \\
\hline $\begin{array}{c}\text { Q16 } \\
\text { Encaminhamento de reclamação ou } \\
\text { denúncia contra as Forças Armadas e/ou } \\
\text { seus integrantes }\end{array}$ & + & Não Significativa \\
\hline $\begin{array}{c}\text { Q17 } \\
\text { Autoavaliação quanto ao nível de } \\
\text { informação sobre as Forças Armadas }\end{array}$ & + & Significativa \\
\hline $\begin{array}{c}\text { Q18 } \\
\text { Importância das Forças Armadas }\end{array}$ & (“não são importantes") & Significativa \\
\hline $\begin{array}{c}\text { Q31 } \\
\text { Participação das Forças Armadas em } \\
\text { missões de paz }\end{array}$ & $\stackrel{+}{+}($ ("concorda") & Não Significativa \\
\hline $\begin{array}{c}\text { Q38 } \\
\text { Respeito das Forças Armadas à } \\
\text { democracia }\end{array}$ & + & Significativa \\
\hline $\begin{array}{c}\text { Q39 } \\
\text { Conhecimento a respeito da Lei da } \\
\text { Anistia }\end{array}$ & (“conhece a lei") & Não Significativa \\
\hline
\end{tabular}

Fonte: Elaboração própria com base em dados do SIPS - Defesa Nacional.

Cumpre explicar em detalhe as hipóteses que sustentam alguns dos resultados previstos no Quadro 2. No caso da variável sexo, a literatura aponta tendência em vários países latino-americanos de uma maior desconfiança de mulheres em relação às instituições militares (MONTALVO, 2009; BELL, 2012). Isso também foi observado em pesquisas realizadas nos Estados Unidos (LEAL, 2005) e no Japão (JAPAN MINISTRY OF DEFENSE, 2012). Para a variável região, entende-se que a confiança deveria ser mais elevada nas regiões do Brasil onde a presença das Forças Armadas é significativa e bem distribuída (Norte e Sul). 
A variável idade (Q1) deveria ter correlação positiva em razão do maior conservadorismo de indivíduos em estratos etários mais avançados, fenômeno observado em países da América Latina (Montalvo, 2009), nos Estados Unidos (LeAL, 2005) e no Japão (JAPAN MiNISTRY Of DefENSE, 2012). A variável escolaridade (Q2) tenderia a ter impacto negativo devido à postura mais crítica de indivíduos mais escolarizados em relação ao papel das Forças Armadas na ruptura da democracia em países da América Latina (MONTALVO, 2009), o que também se aplicaria à variável renda (Q10).

A variável cor/raça (Q3) tenderia a ter pouco impacto sobre a confiança nas Forças Armadas, em linha, por exemplo, com estudos realizados nos Estados Unidos (LEAL, 2005). Contudo, em função da elevada correlação que tal variável possui com as variáveis escolaridade e renda, é possível que a variável cor/raça capte indiretamente os efeitos dessas últimas variáveis. Por essa razão, optou-se por não introduzir no Quadro 2 um resultado esperado para a relação entre cor/raça e confiança nas Forças Armadas.

A variável orgulho de ser brasileiro (Q11) deveria exercer importante efeito no modelo, uma vez que se observa na literatura o papel do patriotismo como fator-chave para explicar a confiança nas Forças Armadas (GüRSOY, 2012). No caso dos indivíduos que serviram às Forças Armadas ou possuem parentes/pessoas próximas que tiveram essa experiência (Q12), a confiança deveria ser mais elevada, devido ao espírito de corpo e aos benefícios derivados dessa vinculação, tais como qualificação profissional. Já as variáveis Q13 a Q17, bem como a Q38, dizem respeito à avaliação da população quanto ao desempenho institucional das Forças Armadas, tendo, portanto, efeitos diretos sobre a confiança. Essa dimensão de avaliação também seria captada na questão sobre a importância das Forças Armadas (Q18), que tenderia a ser ampliada entre os indivíduos que mais confiam na instituição.

A variável participação em missões de paz (Q31) representaria um juízo acerca da necessidade e da capacidade dos militares brasileiros de exercerem atividades no exterior sob mandato internacional e, portanto, deveria estar relacionada à confiança nas instituições militares do país. Quanto ao respeito dos militares à democracia (Q38), aqueles indivíduos que percebessem tal respeito como baixo tenderiam a enxergar nos militares um grupo sem apreço pelas instituições democráticas do país e, por isso, não merecedor de confiança. A variável conhecimento da Lei da Anistia (Q39) poderia ser particularmente relevante para explicar a confiança nas Forças Armadas brasileiras, devido ao fato de que essa norma impede a punição de agentes da repressão (e de integrantes de grupos armados de oposição) responsáveis por crimes praticados no período 1961-1979. Nesse caso, o conhecimento da lei deveria influenciar negativamente a confiança manifestada pelos entrevistados nas instituições militares do país.

Por conveniência analítica, optou-se pela separação da variável dependente confiança, originalmente dividida em uma escala ordinal com cinco classes de respostas, em três categorias: $c=1$ (confia totalmente ou muito), $c=2$ (confia razoavelmente) e $c=3$ (confia pouco ou não confia). Esse mesmo procedimento foi adotado para todas as variáveis explicativas cujas categorias apresentavam uma escala de gradação original de cinco valores, quais sejam: Q11, Q13-Q17 e Q38. Para as demais variáveis, foram mantidas as categorias ou faixas de valores conforme o padrão adotado no questionário SIPS - Defesa Nacional (ver Apêndice). 
Desse modo, o modelo logit cumulativo para $Y_{i}$ (variável resposta para a observação i) pode ser descrito conforme a equação (1) (VENABLES; RIPLEY, 2002):

$$
\operatorname{Ln}\left(\frac{P\left(Y_{i} \leq c\right)}{1-P\left(Y_{i} \leq c\right)}\right)=\zeta_{c}-x_{i}^{\top} \beta
$$

em que: $\zeta_{c}$ é o intercepto da categoria $c ; x_{i}^{\top}$ é o vetor transposto de variáveis indicadoras correspondentes às variáveis explicativas; e $\beta$ é o vetor de parâmetros.

\section{Estimação e avaliação do modelo}

Ajustando-se o modelo para as variáveis explicativas propostas, observa-se pela análise de deviance, na Tabela 1, que, para as variáveis escolaridade $(\mathrm{Q} 2)$, renda $(\mathrm{Q} 10)$, relação com o serviço militar (Q12) e conhecimento da Lei da Anistia (Q39), não há diferenciação significativa entre os níveis. Em razão disso, essas variáveis foram retiradas do modelo, restando somente 13 variáveis independentes em sua versão reduzida.

Tabela 1

Análise de deviance do modelo com todas as variáveis

\begin{tabular}{|c|c|c|c|}
\hline Variável & $\mathrm{X}^{2}{ }_{\mathrm{RV}}$ & G.L. & P-valor \\
\hline Sexo & 29.51 & 1 & $5.56 \mathrm{e}-08$ \\
\hline Região & 9.95 & 4 & 0.0412818 \\
\hline Q1 & 23.93 & 5 & 0.0002243 \\
\hline Q2 & 4.16 & 6 & 0.654887 \\
\hline Q3 & 8.95 & 4 & 0.0624224 \\
\hline Q10 & 1.89 & 8 & 0.7569047 \\
\hline Q11 & 43.91 & 2 & $2.93 \mathrm{e}-10$ \\
\hline Q12 & 0.13 & 2 & 0.9359625 \\
\hline Q13 & 61.84 & 2 & $3.73 \mathrm{e}-14$ \\
\hline Q14 & 12.54 & 2 & 0.0018969 \\
\hline Q15 & 36.67 & 2 & $1.09 \mathrm{e}-08$ \\
\hline Q16 & 13.51 & 2 & 0.0011645 \\
\hline Q17 & 48.07 & 2 & $3.64 \mathrm{e}-11$ \\
\hline Q18 & 16.63 & 2 & 0.000245 \\
\hline Q31 & 3.65 & 1 & 0.0561947 \\
\hline Q38 & 84.05 & 2 & $<2.2 \mathrm{e} \cdot 16$ \\
\hline Q39 & 0.43 & 2 & 0.8064146 \\
\hline
\end{tabular}

Fonte: Elaboração própria com base nos dados do SIPS - Defesa Nacional. 
$\mathrm{Na}$ Tabela 2 encontram-se os valores para os fatores de inflação de variância generalizada $\left(\right.$ GVIF) ${ }^{3}$. Mesmo com todas as variáveis preditoras incluídas no modelo e os valores ajustados pelos graus de liberdade $\left[\operatorname{GVIF}^{\wedge}\left(1 /\left(2^{*} D f\right)\right)\right]$, esses valores ainda permaneceram bastante próximos da unidade, indicando que não há problemas de colinearidade na matriz de delineamento do modelo.

Tabela 2

Fator de inflação de variância generalizado do modelo completo

\begin{tabular}{|c|c|c|c|}
\hline Variável & GVIF & Df & GVIF^(1/(2*Df) $^{\wedge}$ \\
\hline Sexo & 1.114 & 1 & 1.055 \\
\hline Região & 1.883 & 4 & 1.082 \\
\hline Q1 & 1.491 & 5 & 1.041 \\
\hline Q2 & 1.870 & 6 & 1.054 \\
\hline Q3 & 1.424 & 4 & 1.045 \\
\hline Q10 & 1.582 & 8 & 1.059 \\
\hline Q11 & 1.131 & 2 & 1.031 \\
\hline Q12 & 1.162 & 2 & 1.038 \\
\hline Q13 & 1.367 & 2 & 1.081 \\
\hline Q14 & 1.333 & 2 & 1.075 \\
\hline Q15 & 1.120 & 2 & 1.029 \\
\hline Q16 & 1.209 & 2 & 1.049 \\
\hline Q17 & 1.191 & 2 & 1.045 \\
\hline Q18 & 1.078 & 2 & 1.019 \\
\hline Q31 & 1.147 & 1 & 1.071 \\
\hline Q38 & 1.143 & 2 & 1.034 \\
\hline Q39 & 1.285 & 2 & 1.065 \\
\hline
\end{tabular}

Fonte: Elaboração própria com base nos dados do SIPS - Defesa Nacional.

Como anteriormente mencionado, com base nos resultados da Tabela 1, definiu-se o modelo final sem as variáveis Q2, Q10, Q12 e Q39. Uma vez ajustado o modelo com as variáveis restantes, apresentam-se na Tabela 3 as estimativas dos parâmetros, com os respectivos erros-padrão:

\footnotetext{
3 Essa estatística é uma medida de multicolinearidade para modelos lineares. Entretanto, também pode ser utilizada nesse contexto, uma vez que diz respeito apenas às correlações entre preditores (Fox; MonETTE, 1992).
} 
CERATTI, R. K.; MORAES, R. F.; SILVA FILHO, E. B. Confiança nas Forças Armadas...

Tabela 3

Estimativas dos parâmetros do modelo selecionado

\begin{tabular}{|c|c|c|c|c|c|}
\hline Variável & Categoria & Estimativa & $\begin{array}{l}\text { Erro- } \\
\text { Padrão }\end{array}$ & Estatística t & P-valor \\
\hline \multirow{5}{*}{ Q1 } & 2 & $-0,11$ & 0,12 & $-0,91$ & 0,362 \\
\hline & 3 & 0,01 & 0,12 & 0,11 & 0,912 \\
\hline & 4 & $-0,52$ & 0,12 & $-4,24$ & $<0,0001$ \\
\hline & 5 & $-0,38$ & 0,14 & $-2,82$ & 0,005 \\
\hline & 6 & $-0,50$ & 0,14 & $-3,56$ & $<0,0001$ \\
\hline \multirow{4}{*}{ Q3 } & 2 & 0,11 & 0,11 & 1,02 & 0,309 \\
\hline & 3 & $-0,09$ & 0,32 & $-0,27$ & 0,788 \\
\hline & 4 & 0,05 & 0,09 & 0,57 & 0,569 \\
\hline & 5 & 1,38 & 0,48 & 2,86 & 0,004 \\
\hline \multirow{2}{*}{ Q11 } & 2 & 0,26 & 0,09 & 2,88 & 0,004 \\
\hline & 3 & 0,75 & 0,12 & 6,22 & $<0,0001$ \\
\hline \multirow{2}{*}{ Q13 } & 2 & 0,62 & 0,09 & 7,07 & $<0,0001$ \\
\hline & 3 & 1,04 & 0,16 & 6,61 & $<0,0001$ \\
\hline \multirow{2}{*}{ Q14 } & 2 & 0,06 & 0,09 & 0,63 & 0,529 \\
\hline & 3 & 0,32 & 0,10 & 3,39 & 0,001 \\
\hline \multirow{2}{*}{ Q15 } & 2 & $-0,23$ & 0,10 & $-2,25$ & 0,024 \\
\hline & 3 & $-0,49$ & 0,08 & $-6,05$ & $<0,0001$ \\
\hline \multirow{2}{*}{ Q16 } & 2 & 0,26 & 0,12 & 2,07 & 0,038 \\
\hline & 3 & 0,30 & 0,09 & 3,26 & 0,001 \\
\hline \multirow{2}{*}{ Q17 } & 2 & 0,62 & 0,13 & 4,84 & $<0,0001$ \\
\hline & 3 & 0,90 & 0,12 & 7,36 & $<0,0001$ \\
\hline \multirow{2}{*}{ Q18 } & 2 & 0,19 & 0,11 & 1,75 & 0,081 \\
\hline & 3 & 1,01 & 0,21 & 4,86 & $<0,0001$ \\
\hline Sexo & M & $-0,45$ & 0,07 & $-6,21$ & $<0,0001$ \\
\hline \multirow{4}{*}{ Região } & Nordeste & $-0,28$ & 0,14 & $-1,95$ & 0,051 \\
\hline & Norte & $-0,03$ & 0,18 & $-0,15$ & 0,878 \\
\hline & Sudeste & $-0,12$ & 0,14 & $-0,88$ & 0,376 \\
\hline & Sul & 0,20 & 0,17 & 1,17 & 0,243 \\
\hline Q31 & 2 & 0,21 & 0,09 & 2,2 & 0,028 \\
\hline \multirow{2}{*}{ Q38 } & 2 & 0,52 & 0,08 & 6,28 & $<0,0001$ \\
\hline & 3 & 0,90 & 0,10 & 9,22 & $<0,0001$ \\
\hline \multirow{2}{*}{ Intercepto } & 1 & 1,20 & 0,23 & 5,17 & $<0,0001$ \\
\hline & 2 & 3,02 & 0,24 & 12,74 & $<0,0001$ \\
\hline
\end{tabular}

Fonte: Elaboração própria com base nos dados do SIPS - Defesa Nacional. 
Para uma avaliação preliminar acerca da adequação do modelo para fins preditivos, empregou. se a medida $R^{2}$ de Nagelkerke (NAGELKERKE, 1991). Embora o valor obtido de 0,229 possa ser considerado baixo, optou-se por conservar o modelo uma vez que não há consenso na literatura a respeito da validade de medidas como o coeficiente de determinação para a avaliação de modelos para variáveis categorizadas.

Os gráficos apresentados nas Figuras 1, 2, 3 e 4 a seguir mostram os efeitos marginais encontrados para as variáveis explicativas ${ }^{4}$ :

Figura 1

Efeitos marginais da variável Q1 (idade)

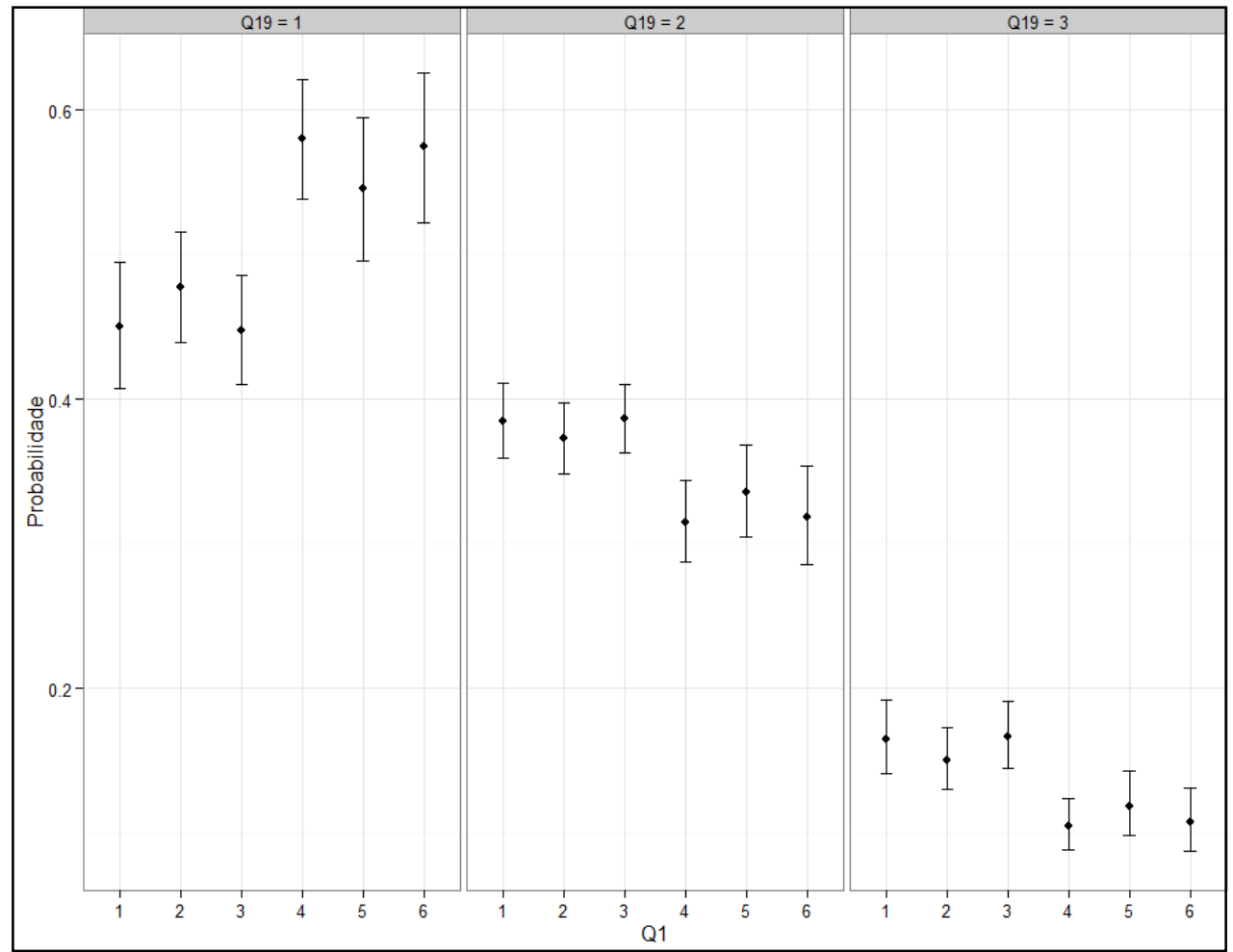

Fonte: Elaboração própria com base nos dados do SIPS - Defesa Nacional.

\footnotetext{
${ }^{4}$ Nos gráficos a seguir, as categorias de cada variável são apresentadas em letras e algarismos para facilitar a visualização dos resultados. A identificação de cada categoria correspondente a esses caracteres se encontra no Quadro 1.
} 
Figura 2

Efeitos marginais das variáveis Q3 (cor/raça), Q11 (orgulho de ser brasileiro), sexo e região
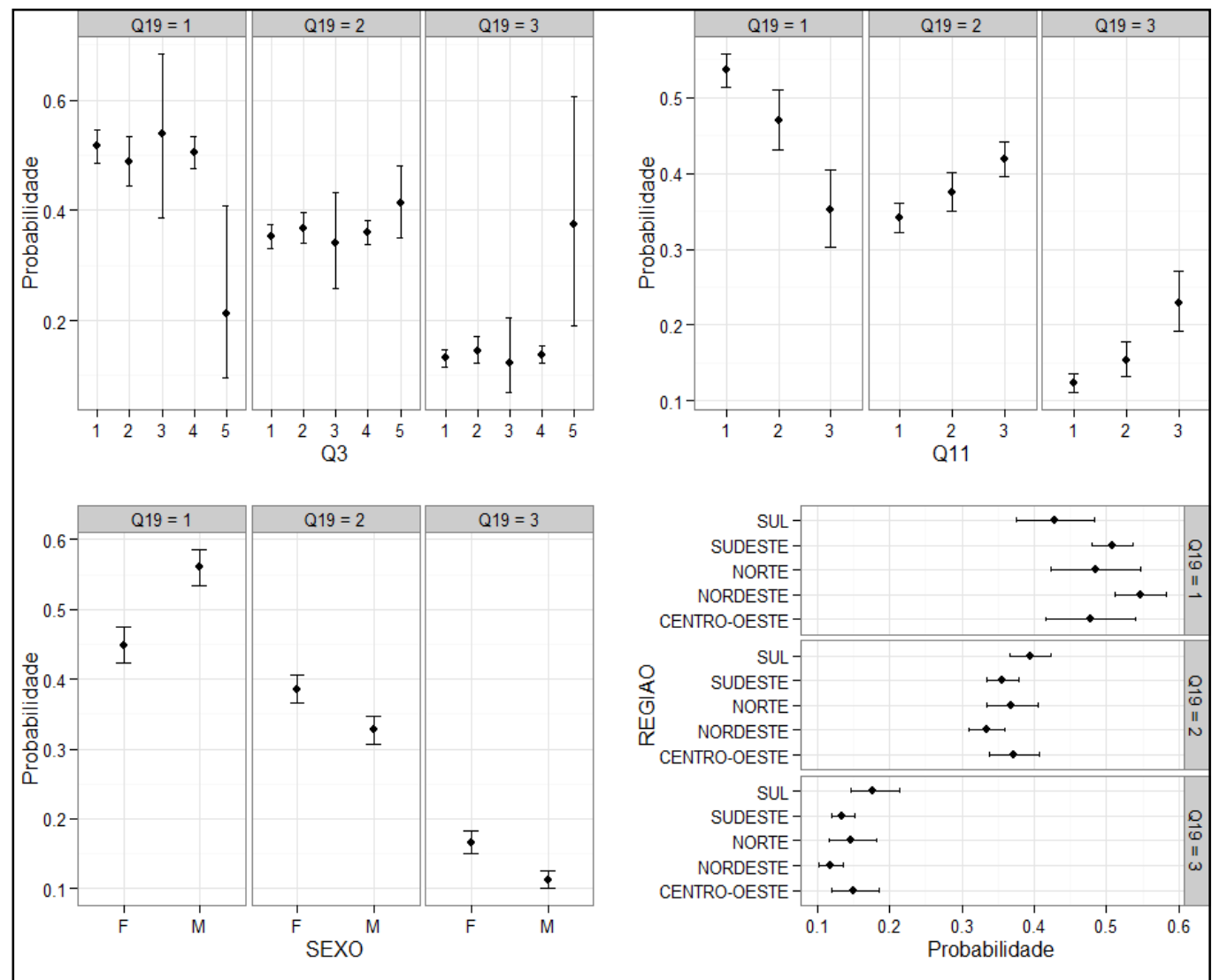

Fonte: Elaboração própria com base nos dados do SIPS - Defesa Nacional. 
Figura 3

Efeitos marginais das variáveis Q13 (avaliação do trabalho das Forças Armadas), Q14 (avaliação da quantidade de informações disponíveis sobre as Forças Armadas), Q15 (avaliação da igualdade de tratamento conferido pelas Forças Armadas), Q16 (encaminhamento de reclamação ou denúncia), Q17 (autoavaliação quanto ao nível de informação) e Q18 (importância das Forças Armadas)
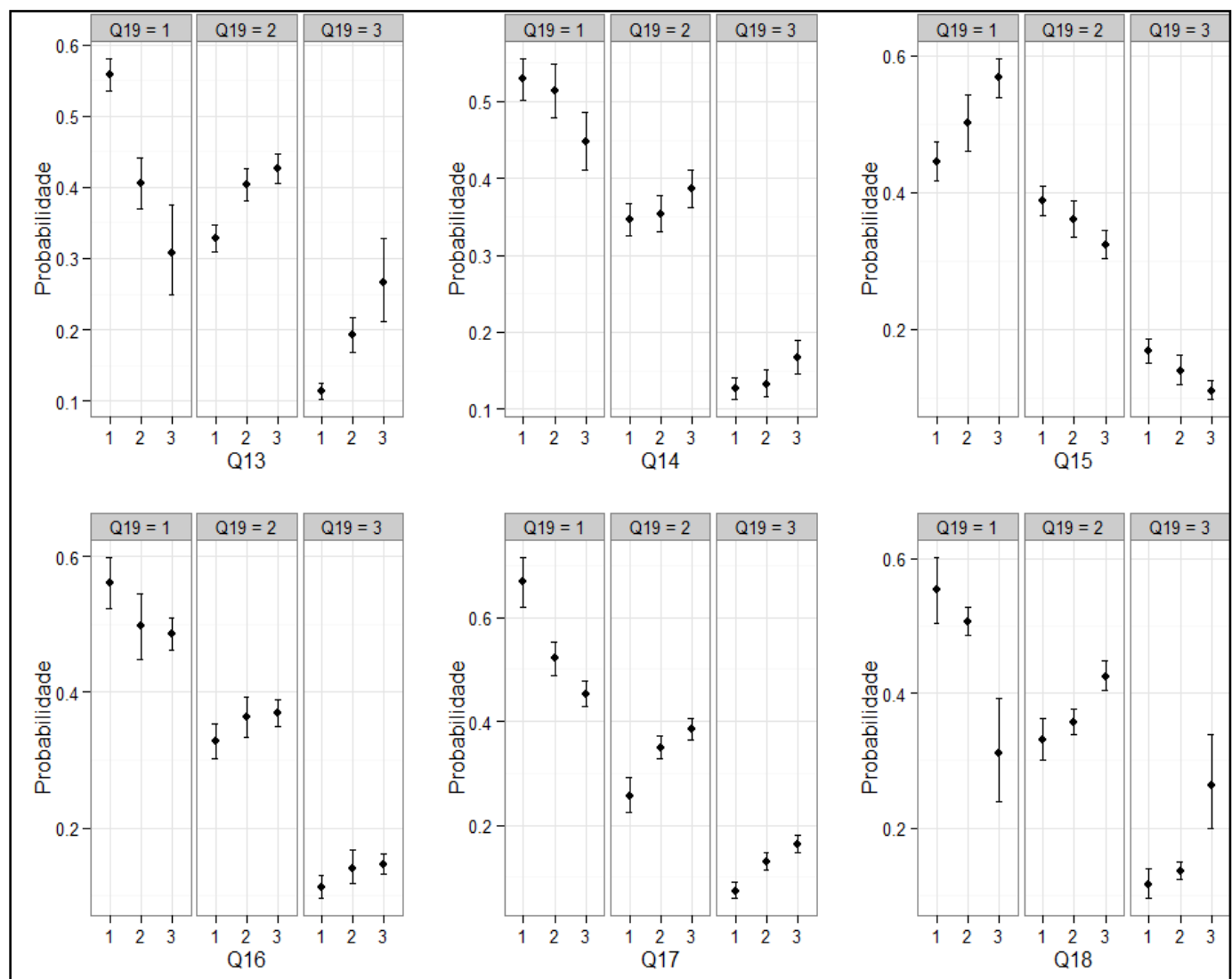

Fonte: Elaboração própria com base nos dados do SIPS - Defesa Nacional. 
Figura 4

Efeitos marginais das variáveis Q31

(participação das Forças Armadas em missóes de paz) e

Q38 (respeito das Forças Armadas à democracia)

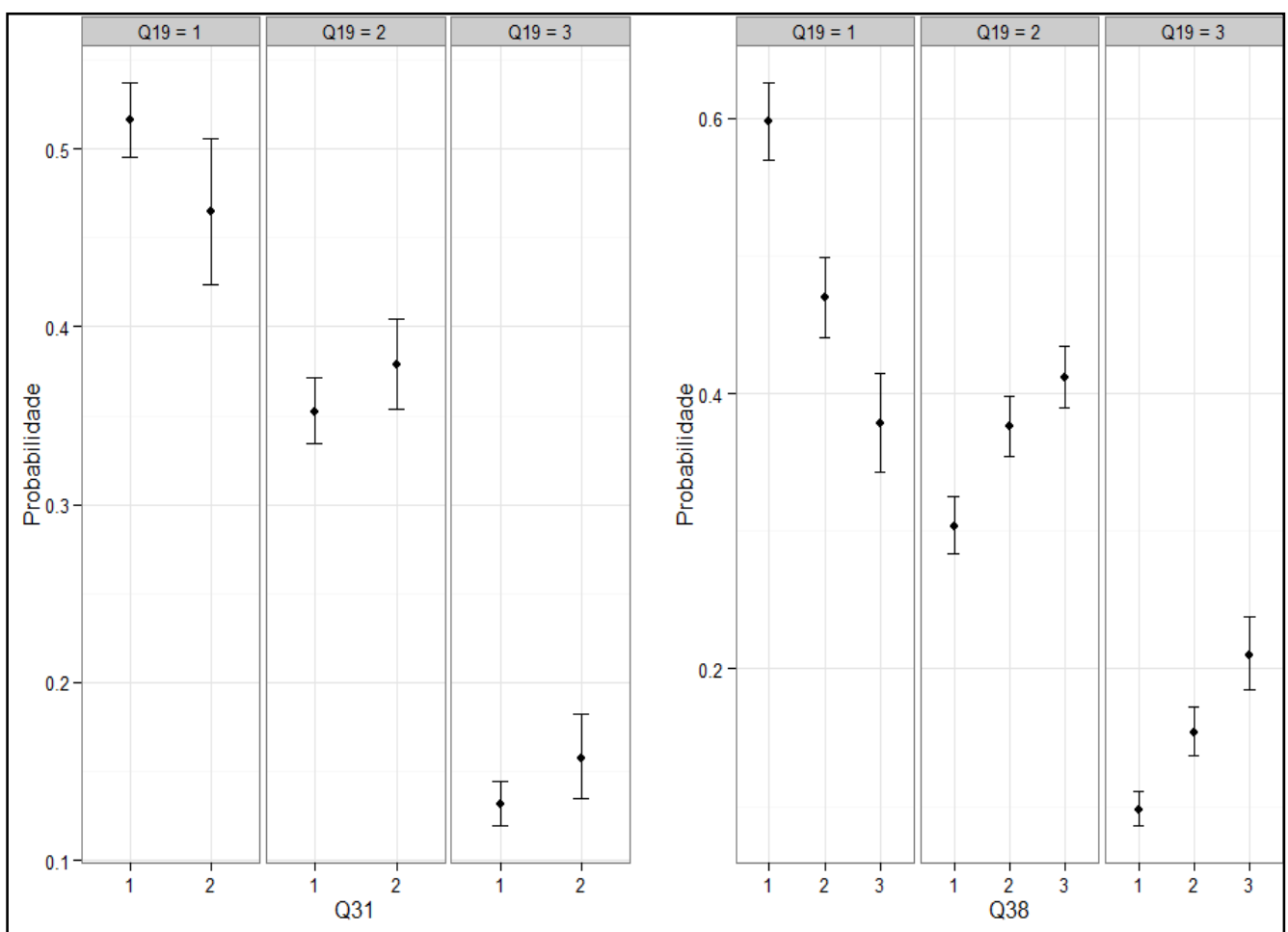

Fonte: Elaboração própria com base nos dados do SIPS - Defesa Nacional.

\section{Análise dos resultados}

A maior parte dos resultados obtidos se mostrou consonante com as hipóteses que embasaram a construção do modelo (Quadro 2).

Para a variável idade (Q1) - Figura 1 -, verifica-se que grupos etários mais avançados tendem a ser mais propensos a mostrar confiança nas Forças Armadas brasileiras que os mais jovens, conclusão que se assemelha às de: Montalvo (2009) e Latinobarómetro (2010), para diversos países da América Latina; Leal (2005) e Jedwab (2010), sobre os Estados Unidos; Jedwab (2010), para o Canadá; Manigart (2001, p. 5), em pesquisa feita em países da União Europeia; Natcen Social Research (2012), sobre o Reino Unido; e Japan Ministry of Defense (2012), sobre o Japão. No caso brasileiro, observa-se uma ruptura de tendência entre as faixas de 35.44 anos (categoria 3) e 45.54 anos (categoria 4) para os respondentes que disseram confiar nas Forças Armadas, sendo a probabilidade de confiança significativamente maior a partir dessa última faixa etária. 
Com relação à variável sexo (Figura 2), indivíduos do sexo masculino tendem a apresentar maior confiança nas Forças Armadas que os do sexo feminino, o que se coaduna com as conclusões de Montalvo (2009) sobre a América Latina. Em estudo realizado por esse autor, a variável sexo foi a de maior impacto sobre o grau de confiança nas Forças Armadas. Conclusão semelhante foi a de Leal (2005) em relação ao caso dos Estados Unidos, onde mulheres apoiam menos as Forças Armadas e o uso da força do que os homens, assim como no Japão (JAPAN MINISTRY OF DefenSE, 2012), onde as mulheres possuem visão mais negativa sobre as Forças Armadas que os homens. Em estudo realizado no Reino Unido, contudo, não se observaram diferenças significativas entre homens e mulheres quanto à visão sobre as Forças Armadas do país (NATCEN SOCIAL RESEARCH, 2012).

Para a variável orgulho de ser brasileiro (Q11) - Figura 2 -, há uma forte separação na avaliação da confiança: aqueles entrevistados que se dizem extremamente ou muito orgulhosos tendem a apresentar maior confiança que os demais grupos de respondentes, conclusão semelhante à de Gürsoy (2012).

Para os itens de opinião, avaliações ruins acerca do trabalho realizado pelas Forças Armadas (Q13) levam à maior propensão a confiar razoavelmente ou pouco nestas. A percepção quanto à escassez de informação sobre as atividades dos militares nos meios de comunicação (Q14) tende, por sua vez, a ter impacto menor na diminuição da confiança: entre entrevistados que avaliaram haver pouca ou nenhuma informação sobre o tema, a probabilidade de confiar totalmente ou muito nas Forças Armadas do país ainda é superior a $40 \%$ (Figura 3). Por sua vez, os entrevistados que afirmaram possuir baixo grau de conhecimento sobre as Forças Armadas e suas atividades (Q17) tendem a confiar menos na instituição.

Com relação ao tratamento dispensado pelas Forças Armadas aos cidadãos (Q15), quando se avalia que este é igualitário, há maior propensão a confiar na instituição. 0 mesmo se aplica acerca da percepção quanto à facilidade de encaminhar reclamação ou denúncia (Q16).

Quando se considera a importância atribuída pelos entrevistados às Forças Armadas (Q18), observa-se uma diferença no efeito marginal entre os que confiam totalmente/muito nas Forças Armadas e as demais categorias, que apresentam menor confiança nessa instituição. Os indivíduos que acreditam que as Forças Armadas respeitam a democracia (Q38) - Figura 4 -, por sua vez, tendem a mostrar maior grau de confiança em comparação aos que não consideram que os militares respeitem as instituições democráticas.

Chamam atenção algumas variáveis que contrariaram a expectativa inicial. Dentre elas, houve reduzido impacto dos níveis de escolaridade (Q2) e renda (Q10) sobre a confiança nas Forças Armadas. Em comparação, o mesmo também ocorre nos Estados Unidos, conforme atestado por Leal (2005). Na América Latina, contudo, o modelo proposto por Montalvo (2009) não foi capaz de comprovar a existência de tal relação. Outro ponto de destaque é o impacto não significativo sobre a confiança nas Forças Armadas encontrado para atributos como participação do entrevistado no serviço militar (ou conhecimento de pessoa próxima que participou) (Q12) e conhecimento da Lei da Anistia (Q39). Embora houvesse expectativa de que esses fatores condicionassem mais fortemente o grau de confiança dos entrevistados nas instituições militares, os resultados obtidos contrariaram essa previsão. A participação 
dos militares brasileiros em missões de paz (Q31) - Figura 4 - também não parece afetar de forma significativa a confiança depositada pela população nas Forças Armadas.

Outro resultado a ser destacado é o nível menor de confiança nas Forças Armadas encontrado na região Sul do país (Figura 2), onde há elevada quantidade de unidades militares estacionadas e onde estas estão relativamente bem distribuídas no território. Considerando o grau substancialmente mais elevado de confiança nas regiões Norte (onde a presença militar é ampla e distribuída) e Nordeste (onde não é ampla), infere-se que a confiança nas Forças Armadas não se relaciona com o número e a distribuição de unidades militares em uma determinada região.

Por fim, há pouca variação na confiança em função da cor/raça (Q3) informada pelo entrevistado. A maior amplitude dos intervalos de probabilidade para os grupos de cor amarela e indígenas se explica pela pequena quantidade de indivíduos em comparação ao tamanho da amostra. Embora as distinções por cor/raça nos Estados Unidos, para fins estatísticos, sejam diferentes das brasileiras, o estudo de Leal (2005) constatou que afro-americanos e latinos não tendem a confiar menos nas Forças Armadas que integrantes de outras etnias/raças, o que, guardadas as devidas proporções, é semelhante ao observado no Brasil.

O modelo proposto explica, por um lado, parte dos elementos que compõem a confiança do brasileiro nas Forças Armadas, demonstrando a associação entre a confiança e as seguintes variáveis: sexo, região, idade, orgulho em ser brasileiro, avaliação do trabalho das Forças Armadas, avaliação acerca da quantidade de informações disponíveis, avaliação sobre a igualdade de tratamento por parte das Forças Armadas, percepção sobre a facilidade de encaminhar reclamação ou denúncia, autoavaliação quanto ao nível de informação sobre as Forças Armadas, importância atribuída às Forças Armadas e respeito dos militares à democracia. Por outro lado, não foi possível confirmar a existência de associação entre algumas variáveis do modelo e a confiança nas Forças Armadas, quais sejam: escolaridade, cor/raça, renda, participação do entrevistado no serviço militar (ou conhecimento de pessoa próxima que participou), participação das Forças Armadas em missões de paz e conhecimento da Lei da Anistia. Não se pode afirmar, particularmente, que a elevada confiança nas Forças Armadas seja um fenômeno de elite, nem tampouco uma característica presente em classes com renda baixa, uma vez que ela se acha distribuída entre praticamente todos os estratos de renda e escolaridade da sociedade.

Seria relevante para o aprimoramento futuro do modelo a inclusão de variáveis que refletissem posturas político-ideológicas dos indivíduos, tais como sua posição no espectro ideológico (esquerda, centro, direita etc.), filiações religiosas e opiniões sobre temas-chave que dominam o debate acerca do papel a ser desempenhado pelos militares no país. Essas variáveis poderiam ter elevado poder explicativo sobre o grau de confiança nas Forças Armadas, a exemplo dos estudos de Gürsoy (2012), analisando o caso da Turquia, e Castillo, Miranda e Torres (2011, p. 17-18), para o caso do Chile.

\section{Considerações Finais}

Este artigo consistiu em um esforço preliminar para avançar na pesquisa empírica sobre o tema da confiança nas Forças Armadas brasileiras, tomando por base os dados coletados pelo SIPS - Defesa 
Nacional. A partir do modelo do questionário aplicado nesta pesquisa de abrangência nacional, foram selecionadas as questões que continham as variáveis consideradas mais relevantes para a determinação da confiança nas instituições militares, de acordo com a literatura sobre o tema.

Os resultados obtidos mostram que, não obstante prevaleça na população um elevado nível de confiança, certos atributos socioeconômicos se mostram mais relevantes para a determinação das variações encontradas.

O aprimoramento do modelo estatístico permitirá o aprofundamento posterior da agenda de pesquisa sobre a confiança nas instituições militares no Brasil. Para tanto, deve-se buscar, em um primeiro momento, ampliar a robustez e a capacidade explanatória do modelo por meio da incorporação ou exclusão de variáveis para, posteriormente, inferir relações de causalidade a partir dos resultados obtidos e de teorias consolidadas sobre o tema. Futuras investigações são necessárias para abordar as possíveis razões por detrás do grau de confiança dos indivíduos nas Forças Armadas. Nesse sentido, ainda que não haja variância significativa quanto ao grau de confiança entre indivíduos de diferentes níveis de renda e escolaridade, as motivações para essa confiança ainda podem ser distintas. É possível que, para níveis mais baixos de escolaridade ou renda, a confiança derive, sobretudo, das chamadas "ações sociais" das Forças Armadas, enquanto para estratos mais elevados ela pode ser resultado da percepção de que as Forças Armadas constituem uma espécie de "reserva moral da nação". Assim, uma pesquisa posterior, que seja capaz de melhor captar o nível de conhecimento da população sobre as atividades desempenhadas pelos militares, bem como suas preferências políticas, seria essencial para a identificação mais precisa dos determinantes dessa confiança.

\section{Referências Bibliográficas}

BeLL, B. “¿Cuándo mucha corrupción justifica um golpe militar?” Perspectias desde el Barómetro de las Américas, $n^{\circ} 79$, 2012. Disponível em: <http://www.vanderbilt.edu/lapop/insights/IO879es.pdf>. Acesso em: 28 ago. 2013.

Bulmahn, T.; FIEBIG, R; HILPERT, C. "Sicherheits und verteidigungspolitisches Meinungsklima in der Bundesrepublik Deutschland" [Opinião pública relacionada às políticas de defesa nacional e segurança da República Federal da Alemanha]. Forschungsbericht, Sozialwissenschaftlichen Instituts der Bundeswehr, n 94, Berlin, may 2011. Disponível em:

<http://www.sowi.bundeswehr.de/resource/resource/MzEzNTM4MmUzMzMyMmUzMTM1MzMyZTM2MzIzMDMwMzAz MDMwMzAzMDY3NzA2MTczNjgzNjM2NjEyMDIwMjAyMDIw/Bevölkerungsumfrage\%202010. farbig\%20Forschungsbericht\%2094_\%202011-06-22.pdf>. Acesso em: 28 ago. 2013.

CAStillo, J. C.; MiRAndA, D.; Torres, P. "Authoritarianism, social dominance and trust in public institutions". Informes Técnicos MIDE-UC, Santiago, n 1107, 2011. Disponível em: <http://mideuc.cl/wp-content/uploads/2011/11/1107. castillo-miranda-torres-2011-trust-SDO-RWA-ISPP.pdf>. Acesso em: 28 ago. 2013.

Fox, J.; MonetTe, G. "Generalized collinearity diagnostics". Journal of the American Statistical Association, vol. 87, $\mathrm{n}^{\circ}$ 417, p. 178-183, mar. 1992.

GalluP. Military and national defense. Washington: Gallup, 2012. Disponível em:

<http://www.gallup.com/poll/1666/military-national-defense.aspx>. Acesso em: 28 ago. 2013.

GogoleWsKa, A. Public image of security, defence and military in Poland. In: VLACHOVÁ, M. (ed.). Public image of security defence and the military in Europe. Belgrade: Geneva Centre for the Democratic Control of Armed Forces, Centre for Civil-Military Relations [Belgrade], 2003. Disponível em:

<http://www.bezbednost.org/upload/document/predstave_javnosti_o_odbrani_i_vojsci_u_centralnoj.pdf>. Acesso em: 28 ago. 2013. 
GüRSOY, Y. Turkish public attitudes toward the military and Ergenekon: consequences for the consolidation of democracy. Istanbul Bilgi University / European Institute, Working Paper, n 5, 2012. Disponível em: <http://eu.bilgi.edu.tr/docs/working_paper_23-05-2012.pdf>. Acesso em: 28 ago. 2013.

HALTINER, K. Tradition as a political value: the public image of security, defense and military in Switzerland. In: VLACHOVÁ, M. (ed.). Public image of security defence and the military in Europe. Belgrade: Geneva Centre for the Democratic Control of Armed Forces, Centre for Civil-Military Relations [Belgrade], 2003. Disponível em: <http://www.bezbednost.org/upload/document/predstave_javnosti_o_odbrani_i_vojsci_u_centralnoj.pdf>. Acesso em: 28 ago. 2013.

Japan Ministry of Defense. Outline of 'Public Opinion Survey on the Self-Defense Forces and Defense Issues'. Tokyo, mar. 2012. Disponível em: <http://www.mod.go.jp/e/d_act/others/pdf/public_opinion.pdf>. Acesso em: 28 ago. 2013.

JeDWAB, J. Trust and confidence in Armed Forces and national government: US, Canada, Spain and Germany. Montréal, dez. 2010. Disponível em: <http://www.acs.

aec.ca/pdf/polls/Trust\%20and\%20Confidence\%20in\%20Armed\%20Forces\%20n\%20four\%20countries.pptx>. Acesso em: 28 ago. 2013

KISS, Z. L. Changes of the Hungarian public opinion on security, defence and the military. In: VLACHOVA, M. (ed.). Public image of security defence and the military in Europe. Belgrade: Geneva Centre for the Democratic Control of Armed Forces; Centre for Civil-Military Relations [Belgrade], 2003. Disponível em:

<http://www.bezbednost.org/upload/document/predstave_javnosti_o_odbrani_i_vojsci_u_centralnoj.pdf>. Acesso em: 28 ago. 2013.

LATINOBARÓMETRO. Latinobarómetro: Matriz de Datos STATA. Santiago, 2010. Disponível em: <http://www.latinobarometro.org/latino/LATDatos.jsp>. Acesso em: 28 ago. 2013.

LEAL, D. L. "American public opinion toward the military: differences by race, gender, and class?". Armed Forces \& Society, vol. 32, n 1, out. 2005. Disponível em: <https://webspace.utexas.edu/lealdl3/AFS.2005.pdf>. Acesso em: 28 ago. 2013.

Manigart, P. Public opinion and European defense. Bruxelles, jul. 2001. Disponível em: <http://ec.europa.eu/public_opinion/archives/ebs/ebs_146_en.pdf>. Acesso em: 28 ago. 2013.

Montalvo, D. "Do you trust your Armed Forces?". Americas Barometer Insights, n² 29, 2009. Disponível em: <http://www.vanderbilt.edu/lapop/insights/I0827en.pdf>. Acesso em: 28 ago. 2013.

NAGELKERKE, N. J. D. "A note on a general definition of the coefficient of determination". Biometrika, vol. 78, n 3, p. 691 692,1991

Natcen Social Research. Public opinion of the UK Armed Forces. London, 2012. Disponível em: <http://bsa. 29. natcen.ac.uk/read-the-report/armed-forces/public-opinion.aspx>. Acesso em: 28 ago. 2013.

NUÑEZ, N. M. "Apoyo público a operaciones militares: factores clave". Cuadernos de Estrategia, Madrid, $\mathrm{n}^{\circ}$ 148, ago. 2010. Disponível em: <http://www.portalcultura.mde.es/Galerias/publicaciones/fichero/CE_148.pdf>. Acesso em: 28 ago. 2013.

Oliveira Júnior, A.; Silva Filho, E. B.; Moraes, R. F. Sistema de Indicadores de Percepção Social (SIPS). Brasília, fev. 2012. Disponível em: <http://www.ipea.gov.br/portal/images/stories/PDFs/SIPS/120418_sips_metodologia.pdf>. Acesso em: 28 ago. 2013.

Pew Research Center. Public esteem for military still high. Washington, D.C., 11 jul. 2013. Disponível em: <http://www.pewforum.org/2013/07/11/public-esteem-for-military-still-high>. Acesso em: 28 ago. 2013.

U.K. Ministry of Defence. Public opinion surveys: 1999 to 2010. London, 2012. Disponível em: <http://www.mod.uk/Defencelnternet/AboutDefence/CorporatePublications/ConsultationsandCommunications/Surveys /POS>. Acesso em: 28 ago. 2013.

VenaBles, W. N.; RIPLeY, B. D. Modern applied statistics with S. 4ª ed. New York: Springer, 2002.

VLACHOVÁ, M. (ed.). Public image of security defence and the military in Europe. Belgrade: Geneva Centre for the Democratic Control of Armed Forces, Centre for Civil-Military Relations [Belgrade], 2003. Disponível em: <http://www.bezbednost.org/upload/document/predstave_javnosti_o_odbrani_i_vojsci_u_centralnoj.pdf>. Acesso em: 28 ago. 2013. 


\section{Apêndice}

\section{Formulário SIPS - Defesa Nacional}

$N^{\circ}$ de identificação:

Nome:

Telefone:

Sexo:

Município:

UF:

Latitude:

Longitude:

Data:

INSTRUÇÃO: Conversar com pessoas maiores de 18 anos. Caso não tenha 18 anos, perguntar se tem alguém em casa com mais de 18 anos que possa falar.

\section{PERGUNTAS}

1. Qual a sua idade (em anos completos)?

1. Idade:

88 Não sabe

99 Não respondeu

2. Qual o seu nível de escolaridade?

1. Não escolarizado(a)

2. Ensino fundamental incompleto

3. Ensino fundamental completo

4. Ensino médio incompleto

5. Ensino médio completo

6. Ensino superior incompleto

7. Ensino superior completo ou pós-graduação

88 Não sabe

99 Não respondeu

3. Qual a sua cor ou raça?

1. Branca

2. Preta

3. Amarela (origem japonesa, chinesa, coreana etc.)

4. Parda

5. Indígena

88 Não sabe

99 Não respondeu

4. Qual é o seu estado civil?

1. Casado(a)

2. Desquitado(a) ou separado(a) judicialmente

3. Divorciado(a)

4. Viúvo(a)

5. Solteiro(a)

88 Não sabe

99 Não respondeu

5. Na semana passada o (a) $\operatorname{Sr}(a)$.:

1. Tinha um trabalho remunerado

2. Tinha um trabalho remunerado do qual estava temporariamente afastado por algum motivo (férias, licença, greve, doença etc.)

3. Exerceu apenas tarefas em cultivo, pesca ou criação de animais destinados à própria alimentação das pessoas moradoras no domicílio

4. Exerceu apenas tarefas de construção, destinada ao próprio uso das pessoas moradoras do domicílio

5. Exerceu outro tipo de atividade não remunerada

6. Exerceu apenas tarefas domésticas no próprio domicílio

7. Não trabalhou e não procurou trabalho remunerado (inativo)

8. Não trabalhou, mas procurou trabalho remunerado (desempregado)

88 Não sabe

99 Não respondeu 
6. No trabalho único ou principal da semana passada, o (a) Sr(a). era:

1. Empregado com carteira assinada

2. Empregado sem carteira assinada

3. Servidor público civil ou militar

4. Trabalhador doméstico com carteira assinada

5. Trabalhador doméstico sem carteira assinada

6. Trabalhador por conta própria ou autônomo

7. Empregador

77 NSA (Não Se Aplica)

88 Não sabe

99 Não respondeu

7. Como o (a) Sr(a). se sente em relação à sua vida?

1. Minha vida é muito próxima daquilo que considero ideal

2. Minha vida é razoavelmente próxima daquilo que considero ideal

3. Minha vida não é muito próxima do que considero ideal

4. Minha vida não é nem um pouco próxima do que considero ideal

88 Não sabe

99 Não respondeu

8. Nos últimos 3 anos, o (a) Sr(a). percebe que a renda da sua família:

1. Melhorou muito

2. Melhorou pouco

3. Permaneceu igual

4. Piorou pouco

5. Piorou muito

88 Não sabe

99 Não respondeu

9. O (a) Sr(a). conhece alguém que é beneficiário do Programa Bolsa Família?

1. Não

2. Sim, eu mesmo

3. Sim, alguém da minha família que vive em minha casa

4. Sim, alguém da minha família, mas que não vive em minha casa

5. Sim, alguém que não é da minha família

88 Não sabe

99 Não respondeu

10.1. Considerando todas as pessoas da sua família que vivem em sua casa e todas as fontes de renda, qual foi a renda total obtida no último mês? (Considerar o rendimento líquido total da família e indicar o número de integrantes rendimento familiar per capita; devem ser somadas todas as fontes de renda - salário, aposentadoria, pensão, programas sociais, aluguel, remuneração financeira etc.)

1. Renda:

88 Não sabe

99 Não respondeu

10.2. Qual é o número de integrantes da família que moram na mesma casa?

1. Pessoas:

88 Não sabe

99 Não respondeu

11. O quão orgulhoso o (a) Sr(a). se sente em ser brasileiro(a): extremamente, muito, razoavelmente, pouco ou nada?

1. Extremamente orgulhoso

2. Muito orgulhoso

3. Razoavelmente orgulhoso

4. Pouco orgulhoso

5. Nada orgulhoso

88 Não sabe

99 Não respondeu

12. O (a) Sr(a). está servindo ou já serviu às Forças Armadas (prestando serviço militar obrigatório ou atuando como profissional no Exército, Marinha ou Aeronáutica) ou, então, tem um parente próximo ou uma pessoa próxima que está servindo ou já serviu às Forças Armadas?

1. Está servindo ou já serviu

2. Tem um parente próximo ou pessoa próxima que está servindo ou já serviu

3. Ambas as coisas 
4. Nenhuma das anteriores

88 Não sabe

99 Não respondeu

13. Como o (a) Sr(a). avalia o trabalho realizado pelas Forças Armadas do Brasil, ou seja, o Exército, a Marinha e a Aeronáutica: muito bom, bom, regular, ruim ou muito ruim?

1. Muito bom

2. Bom

3. Regular

4. Ruim

5. Muito ruim

88 Não sabe

99 Não respondeu

14. Como o (a) Sr(a). avalia a quantidade de informações divulgadas nos meios de comunicação - televisão, rádio, jornais, revistas - sobre as Forças Armadas (Exército, Marinha e Aeronáutica): muito boa, boa, regular, ruim, muito ruim?

1. Muito boa

2. Boa

3. Regular

4. Ruim

5. Muito ruim

88 Não sabe

99 Não respondeu

15. Como o (a) Sr(a). avalia a seguinte afirmação: "O tratamento dado pelas Forças Armadas e por seus integrantes (os militares) no relacionamento com os cidadãos civis (as pessoas que estão fora das Forças Armadas) é igual para todos, independente de renda, cor da pele, idade, deficiência ou gênero".

1. Discordo totalmente

2. Discordo

3. Não concordo nem discordo

4. Concordo

5. Concordo totalmente

88 Não sabe

99 Não respondeu

16. Em sua opinião, encaminhar uma reclamação ou denúncia contra as Forças Armadas (Exército, Marinha e Aeronáutica) ou contra algum de seus integrantes seria: muito fácil, fácil, de dificuldade razoável, difícil ou muito difícil? 1. Muito fácil

2. Fácil

3. De dificuldade razoável

4. Difícil

5. Muito difícil

88 Não sabe

99 Não respondeu

17. O quanto o (a) Sr(a). se considera informado sobre as Forças Armadas do Brasil (Exército, Marinha e Aeronáutica) e suas atividades: totalmente, muito, razoavelmente, pouco ou nada?

1. Totalmente informado

2. Muito informado

3. Razoavelmente informado

4. Pouco informado

5. Nada informado

88 Não sabe

99 Não respondeu

18. Parte da população brasileira acredita que as Forças Armadas (Exército, Marinha e Aeronáutica) são importantes para o país, enquanto uma outra parte acredita que elas não são importantes. Em relação à importância das Forças Armadas para o Brasil, com qual das seguintes frases o (a) Sr(a). concorda mais?

1. Elas são importantes apenas no caso de uma guerra

2. Elas são importantes tanto no caso de uma guerra como na ausência de guerras (ou seja, na paz)

3. Elas não são importantes em nenhuma situação

88 Não sabe

99 Não respondeu

19. O quanto o (a) Sr(a). confia nas Forças Armadas: totalmente, muito, razoavelmente, pouco ou nada? 
1. Confio totalmente

2. Confio muito

3. Confio razoavelmente

4. Confio pouco

5. Não confio nada

88 Não sabe

99 Não respondeu

20. Nos últimos anos, algumas pessoas têm debatido o porquê de o Brasil ter Forças Armadas e, também, quais os tipos de trabalho que elas devem fazer. Na sua opinião, quais devem ser as funções das Forças Armadas? (O entrevistado pode escolher quantos itens desejar.)

1. Defender o país em caso de guerra

2. Combater o terrorismo

3. Combater a criminalidade em conjunto com as polícias

4. Ajudar a população com serviços médicos e sociais e em casos de desastres naturais (exemplos: enchentes, deslizamentos de terra, incêndios etc.)

5. Construir estradas, ferrovias, portos etc.

6. Participar de missões de paz em outros países (exemplos: Haiti, países da África)

7. Ensinar aos jovens uma profissão

8. Passar para os jovens valores como responsabilidade e disciplina

9. Nenhuma das anteriores

88 Não sabe

99 Não respondeu

21. Felizmente, o Brasil, hoje em dia, vive em paz com os demais países do mundo. Contudo, se houvesse uma guerra da qual o Brasil participasse, as pessoas poderiam contribuir de várias formas, ou mesmo não contribuir. Caso realmente houvesse uma guerra, gostaria de saber se o (a) Sr(a). estaria disposto(a) a contribuir e de qual maneira.

1. Participaria como militar, inclusive em ações de combate

2. Participaria como militar, mas sem participar de ações de combate (exemplos: apoio administrativo, serviços de saúde, manutenção de equipamentos)

3. Não participaria como militar, mas contribuiria como civil (exemplos: prestando apoio a famílias de militares, trabalhando em organizações não governamentais de apoio a feridos)

4. Não estaria disposto a contribuir de nenhuma forma

88 Não sabe

99 Não respondeu

22. Cada pessoa tem uma percepção própria daquilo que possa ser uma ameaça para ela, para sua família, para sua cidade e para seu país, ou seja, cada pessoa possui certos medos. Assim sendo, de quais das seguintes ameaças o (a) $\mathrm{Sr}(\mathrm{a})$. tem medo? (O entrevistado pode escolher quantos itens desejar.)

1. Guerra com um país vizinho

2. Guerra com uma potência estrangeira (ou seja, um país mais forte que o Brasil)

3. Crime organizado

4. Desastres ambientais e climáticos (exemplos: acidente em usina nuclear, vazamento de petróleo no mar, enchentes, secas, incêndios, deslizamentos de terra)

5. Terrorismo

6. Epidemias (gripe suína, dengue etc.)

7. Outros

8. Nenhuma das anteriores

88 Não sabe

99 Não respondeu

23. A Amazônia brasileira possui muitos recursos naturais, como os minérios, a água e as próprias florestas. O (a) $\operatorname{Sr}(a)$. acredita que o Brasil, nos próximos 20 anos, possa sofrer uma invasão militar estrangeira com o objetivo de controlar os recursos naturais da Amazônia?

1. Acredito totalmente nisso (tenho certeza)

2. Acredito muito nisso

3. Acredito razoavelmente nisso

4. Acredito pouco nisso

5. Não acredito nisso

88 Não sabe

99 Não respondeu

24. Há alguns anos atrás, foi anunciada a descoberta de grandes reservas de petróleo e gás natural a alguns quilômetros do litoral do Brasil, chamadas de reservas do pré-sal. O (a) Sr(a). acredita que o Brasil, nos próximos 20 anos, possa sofrer uma invasão militar estrangeira com o objetivo de controlar essas riquezas?

1. Acredito totalmente nisso (tenho certeza) 
2. Acredito muito nisso

3. Acredito razoavelmente nisso

4. Acredito pouco nisso

5. Não acredito nisso

88 Não sabe

99 Não respondeu

25. Como já foi mencionado, o Brasil, atualmente, vive em paz com os outros países do mundo. Mas e quanto ao futuro? $O$ (a) Sr(a). acha que alguns dos países listados a seguir poderão, nos próximos 20 anos, ser uma ameaça militar para 0 Brasil? (O entrevistado pode escolher quantos itens desejar.)

1. Argentina

2. Bolívia

3. China

4. Colômbia

5. Estados Unidos

6. Índia

7. Países da Europa

8. Paraguai

9. Rússia

10. Venezuela

11. Outros países

12. Nenhum país representará ameaça para o Brasil no futuro

88 Não sabe

99 Não respondeu

26. Atualmente, existem algumas organizações não governamentais estrangeiras trabalhando na Amazônia brasileira. Algumas pessoas afirmam que a presença delas é importante, pois elas contribuem para a defesa do meio ambiente e para proteger os direitos humanos ou as minorias, como os índios. Outras pessoas, contudo, dizem que estas organizações defendem interesses de outros países e não os do Brasil. Na sua opinião, a influência das organizações não governamentais estrangeiras na Amazônia brasileira é: muito positiva, positiva, nem positiva nem negativa, negativa ou muito negativa?

1. Muito positiva

2. Positiva

3. Nem positiva nem negativa (não influenciam nem de uma forma nem de outra)

4. Negativa

5. Muito negativa

88 Não sabe

99 Não respondeu

27. Em alguns países vizinhos, ocorrem conflitos violentos. São casos desse tipo: os conflitos entre governo e guerrilhas na Colômbia, Paraguai e Peru; os conflitos sociais na Bolívia; e as disputas políticas entre Colômbia, Venezuela e Equador. O (a) Sr(a). acha que esses conflitos podem afetar o Brasil? Sim ou não?

1. Sim

2. Não

88 Não sabe

99 Não respondeu

28. Se for preciso defender o país de uma ameaça estrangeira, as Forças Armadas do Brasil precisam ter certos equipamentos militares, como aviões, navios e tanques de guerra. Em sua opinião, os equipamentos militares que as Forças Armadas possuem atualmente são: muito bons, bons, regulares, ruins ou muito ruins?

1. Muito bons

2. Bons

3. Regulares

4. Ruins

5. Muito ruins

88 Não sabe

99 Não respondeu

29. Na sua opinião, os gastos do governo brasileiro com as Forças Armadas para a aquisição de equipamentos militares devem: aumentar muito, aumentar razoavelmente, permanecer como estão, diminuir razoavelmente ou diminuir muito? 1. Aumentar muito

2. Aumentar razoavelmente

3. Permanecer como estão

4. Diminuir razoavelmente

5. Diminuir muito

88 Não sabe 
99 Não respondeu

30. O governo brasileiro, nos últimos anos, tem buscado ampliar a indústria militar do país, ou seja, as empresas que produzam equipamentos como aviões e navios de guerra, tanques de guerra etc. Para algumas pessoas é importante que o Brasil tenha uma indústria como esta, enquanto para outras isso não tem importância. Como o (a) Sr(a). avalia a importância de haver no Brasil empresas que produzam armamentos?

1. É importante, mas somente se as empresas forem brasileiras

2. É importante, e as empresas podem ser tanto brasileiras como estrangeiras

3. Isto não é importante

88 Não sabe

99 Não respondeu

31. Desde 2004, há uma missão de paz da ONU (Organização das Nações Unidas) no Haiti, um país do Caribe, e o Brasil é o país que mais tem enviado militares para lá. Na sua opinião, as Forças Armadas do Brasil devem participar de missões de paz como estas? Sim ou não?

1. Sim

2. Não

88 Não sabe

99 Não respondeu

32. O (a) Sr(a). acha que alguns dos países listados a seguir serão, nos próximos 20 anos, importantes aliados do Brasil? Ou seja, serão países amigos/parceiros do Brasil? (O entrevistado pode escolher quantos itens desejar.)

1. Argentina

2. Bolívia

3. China

4. Colômbia

5. Estados Unidos

6. Índia

7. Países da Europa

8. Paraguai

9. Rússia

10.Venezuela

11. Outros países

12. Nenhum país será um importante aliado do Brasil nos próximos 20 anos

88 Não sabe

99 Não respondeu

33. Discute-se no Brasil se as Forças Armadas devem combater a criminalidade, ou se esta é uma função que cabe apenas às polícias. Sobre esse assunto, com qual das seguintes frases o (a) Sr(a). concorda mais?

1. As Forças Armadas devem sempre combater a criminalidade

2. As Forças Armadas devem combater a criminalidade apenas em algumas situações

3. Apenas as polícias devem combater a criminalidade

88 Não sabe

99 Não respondeu

34. Quando os jovens vão decidir que tipo de trabalho querem ter no futuro, pensam em várias opçóes. Na opinião do (a) Sr(a)., o quanto a carreira militar, atualmente, é atraente para os jovens: extremamente, muito, razoavelmente, pouco ou nada?

1. Extremamente atraente

2. Muito atraente

3. Razoavelmente atraente

4. Pouco atraente

5. Nada atraente

88 Não sabe

99 Não respondeu

35. Atualmente, o serviço militar no Brasil é obrigatório. Algumas pessoas no Brasil discutem a possibilidade de ser criado um serviço civil para aqueles que não quiserem fazer o serviço militar. No serviço civil, os jovens fariam atividades como a prestação de serviços comunitários, o apoio a populaçóes carentes etc. Qual a sua opinião sobre isso?

1. Deve haver somente o serviço militar obrigatório (como é hoje em dia)

2. Deve haver o serviço militar e o serviço civil. E o jovem deve obrigatoriamente escolher um dos dois (ou seja, o jovem é obrigado a servir, mas escolhe se fará o serviço militar ou o serviço civil)

3. Deve haver o serviço militar e o serviço civil, mas nenhum dos dois deve ser obrigatório (ou seja, seriam apenas voluntários)

4. Não deve haver nem o serviço militar nem o serviço civil, mesmo que sejam voluntários 
88 Não sabe

99 Não respondeu

36. Em muitos países, inclusive no Brasil, algumas pessoas discutem se as mulheres devem ter o direito de fazer parte das Forças Armadas como militares. Alguns são favoráveis, outros são contrários. $O$ (A) Sr(a). concorda em que as mulheres possam ser militares nas Forças Armadas do Brasil (Exército, Marinha, Aeronáutica)?

1. Concordo, inclusive participando de combates militares

2. Concordo, mas sem participar de combates militares, atuando apenas em outras funções (exemplos: apoio, serviços relacionados à saúde, manutenção de equipamentos)

3. Não concordo

88 Não sabe

99 Não respondeu

37. O (a) Sr(a). concorda com a presença de militares homossexuais (gays, lésbicas etc.) nas Forças Armadas do Brasil (Exército, Marinha, Aeronáutica)? Sim ou não?

1. Sim

2. Não

88 Não sabe

99 Não respondeu

38. Na sua opinião, o quanto os militares das Forças Armadas do Brasil respeitam a democracia?

1. Totalmente

2. Muito

3. Razoavelmente

4. Pouco

5. Nada (eles não respeitam a democracia)

88 Não sabe

99 Não respondeu

39. Durante o regime militar no Brasil, que durou de 1964 a 1985, foram cometidos crimes por agentes da repressão (como policiais e militares) e por grupos de oposição. Esses crimes foram perdoados por uma lei de 1979, chamada

"Lei da Anistia". O (a) Sr(a). já tinha ouvido falar sobre esse assunto?

1. Nunca tinha ouvido falar

2. Tinha ouvido falar, mas não sei o que é

3. Ouvi falar e sei o que é

88 Não sabe

99 Não respondeu

40. Atualmente, algumas pessoas têm defendido que a "Lei da Anistia" deve ser revista para que possa haver a investigação e a punição de crimes cometidos durante o regime militar no Brasil. Na sua opinião, esses crimes deveriam ser investigados e/ou punidos?

1. Não deve haver nenhuma investigação

2. Sim, deve haver investigação, mas não deve haver punição para ninguém

3. Sim, deve haver investigação e punição apenas para os agentes da repressão (como policiais e militares, por exemplo)

4. Sim, deve haver investigação e punição apenas para aqueles que participaram de grupos armados de oposição (guerrilheiros, por exemplo)

5. Sim, deve haver investigação e punição para todos os envolvidos

77 NSA (Não Se Aplica)

88 Não sabe

99 Não respondeu

Rubem Kaipper Ceratti - rubem_ceratti@yahoo.com.br

Rodrigo Fracalossi de Moraes ·rodrigo.moraes@ipea.gov.br

Edison Benedito da Silva Filho.edison.benedito@ipea.gov.br

Submetido à publicação em novembro de 2013. Versão final aprovada em julho de 2014. 